\title{
La Educación para la Paz en tiempos de la Covid-19: repensar otras lógicas desde la imaginación, la fantasía, la creatividad y la utopía $^{1}$
}

\section{Peace Education in Times of Covid-19: Rethinking other Kind of Logic from the Imagination, Fantasy, Creativity and Utopia}

\author{
Sofía Herrero Rico ${ }^{2}$ \\ ORCID: https://orcid.org/0000-0003-3289-1883 \\ Universitat Jaume I (España)
}

Recibido: 30-04-2021

Aceptado: 30-08-2021

\section{Resumen}

Este artículo pretende reflexionar sobre los retos de la educación para la paz en la situación de la pandemia global de la Covid-19 desde una mirada positiva, entendida como una nueva oportunidad para que la educación plantee enseñar a hacer las paces desde nuestra cotidianidad; y, de este modo, la humanidad pueda forjar un futuro más pacífico. En este quehacer, se revalorizará el uso de la imaginación, la fantasía y la creatividad como recursos educativos (Rodari 1976,

\footnotetext{
${ }^{1}$ Este artículo es el original del publicado en inglés en Intechopen, en el libro Creativity. A Force of Innovation (Jain 2021)

2 (sherrero@uji.es). Doctora con mención internacional por la Universitat Jaume I (UJI) de Castellón, España. Su Tesis Doctoral Educación para la Paz. El enfoque REM (ReconstructivoEmpoderador) obtuvo el premio extraordinario de Doctorado del curso 2012-13. Máster Internacional en Estudios de Paz, Conflictos y Desarrollo y licenciada en Pedagogía por la Universidad de Valencia.

Coordinadora de la Cátedra UNESCO de Filosofía para la Paz, investigadora del Instituto Interuniversitario de Desarrollo Social y Paz (IUDESP) y miembro del grupo de investigación DESPAZ, Desarrollo Social y Paz (Filosofía, Comunicación, Educación y Ciudadanía).

Ha realizado estancias investigadoras en EEUU, Portugal, Italia, México y Costa Rica e impartido cursos, seminarios, ponencias y talleres tanto a nivel nacional, como internacional, en Perú, Argelia, Italia, México, EEUU, Finlandia y Malta.

Desarrolla su labor docente en el Departamento de Pedagogía de la UJI, en el área de Didáctica y Organización Escolar, donde participa también en varios proyectos de investigación e innovación educativa. Sus principales líneas de investigación son la educación para la paz, los temas educativos transversales como la paz, los valores, la coeducación y las habilidades blandas, la didáctica, las metodologías activas y participativas, la filosofía con niños y niñas y la creatividad. Cuenta con distintas publicaciones, libros, capítulos de libro y artículos en revistas especializadas.
} 
1995; Lederach 2007; Herrero y Vázquez 2018; Herrero 2019; García-González 2019). Asimismo, se propone la utopía como ese horizonte desconocido, todavía por llegar, que nos mostrará, ante tantas dudas e incertidumbres, esos posibles escenarios que nos motiven a seguir trabajando por las culturas de paz. Esta reflexión parte del enfoque Reconstructivo-Empoderador de Educación para la Paz que vengo proponiendo en mis investigaciones como miembro del Instituto Interuniversitario de Desarrollo Social y Paz.

Palabras-clave: Educación, paz, imaginación, fantasía, creatividad, utopía.

\begin{abstract}
This article aims to reflect on the challenges of peace education in times of Covid-19 global pandemic from a positive perspective, understood as a new opportunity for education to consider the teaching of how to make peace from our daily experiences; and in this way, humanity can forge a more peaceful future. In this task, the use of imagination, fantasy and creativity as educational resources will be revalued (Rodari 1976, 1995; Lederach 2007; Herrero and Vázquez 2018; Herrero 2019; García-González 2019). Likewise, utopia is proposed as that unknown horizon, still to come, that will show us, in the face of so many doubts and uncertainties, those possible scenarios which will motivate us to continue working for cultures of peace. This reflection starts from the Reconstructive-Empowering Peace Education approach that I have been proposing in my research as a member of the Interuniversity Institute of Social Development and Peace.
\end{abstract}

Keywords: Education, peace, imagination, fantasy, creativity, Utopia.

\title{
El enfoque Reconstructivo-Empoderador de Educación para la Paz
}

La propuesta del enfoque Reconstructivo-Empoderador (en adelante enfoque REM) de Educación para la Paz nos invita a la reflexión sobre qué lógica y racionalidad hemos instaurado como seres humanos y en la que se asienta, por ende, la educación. Al parecer, desde la política, desde los medios de comunicación, desde la cultura dominante, desde, en general, la interacción de la vida misma, se nos enseña la lógica de la violencia, la destrucción, la competitividad y la exclusión. La exclusión de aquellas, aquellos, aquello que no se acople al molde generalizado, que no corresponda a lo impuesto, a lo estandarizado, a lo considerado como válido, a lo que no nos pertenece, a lo extraño y diferente, y ello conlleva todo tipo de conflictos. Teniendo 
esto en cuenta, el enfoque REM de Educación para la Paz se plantea como una herramienta para poder transformar pacíficamente los conflictos. En este quehacer se destaca, por un lado, nuestras capacidades y competencias para hacer las paces (Martínez Guzmán 2005, 2001) y nuestro empoderamiento para la acción (Muñoz 2000). Por otro lado, se subraya el uso del reconocimiento del otro, de la otra y de lo otro (Honneth 1997, 2008, 2011) y de nuestro pensamiento creativo (Freire 1970; Sátiro 2011, 2018; García-González 2019) para encontrar alternativas positivas.

We have to be at home with our own capacity to fantasize. We need to be able to weave together our knowledge of history, geography, and culture; to imagine a different future. On the one hand, we need analytic knowledge: we need to know what the social scientists and physical scientists can count and measure. We need that, but we need intuition to know when to break loose from conventional categories of thought (Cavin 2006: 401).

En este sentido, la Educación para la Paz desde el enfoque REM pone en cuestión la lógica en la que nos insertamos y la que usamos para entender y transformar los conflictos, ya que sabemos que podemos hacer las cosas de maneras diferentes, tenemos alternativas para hacer las paces. Sabemos que la violencia no es una fatalidad biológica incluida en nuestra genética (Adams 1992), sino que se aprende por procesos de socialización y aculturación, del mismo modo podemos aprender la noviolencia y la paz (López Martínez 2006: 71). Aprender la noviolencia y la paz quiere decir entrar en la lógica de la transformación, invertir el rumbo, aprender a ir contra corriente, romper las reglas del juego injusto de modo imaginativo, creativo, y no destructivo, aprender, en definitiva, otras lógicas que no sean las de la violencia y destructividad, otras lógicas más esperanzadoras, ilusas y fantásticas (Rodari 1976).

El enfoque REM de Educación para la Paz se define, por tanto, como la reconstrucción de nuestras competencias humanas, en el sentido, de capacidades o habilidades para hacer las paces, y nuestro empoderamiento para llevarlas a la acción. Pone de manifiesto que hacer las paces es posible para todas las personas, $\mathrm{y}$, teniendo esto en cuenta, nos reta a buscar alternativas para transformar nuestros conflictos, cotidianos e inherentes a las relaciones humanas. Así, se subvierte la realidad entendida muchas veces por la cultura occidental, la cual nos parece indicar que existe sólo una única lógica, la de responder mediante la violencia y/o destrucción ante cualquier diferencia, desavenencia, choque o conflicto. De este modo, este enfoque, propone, asimismo, desaprender la cultura de la guerra y la violencia (Bastida 1994) y aprender culturas de paz, a través elementos tales como (Herrero Rico 2019): 
- El reconocimiento de todos los seres humanos como interlocutores válidos, reconocimiento que iría desde la integridad física de las personas, los derechos jurídicos, así como las distintas formas y estilos de vida (Honneth 1997, 2008, 2011).

- La capacidad de cambiar nuestras percepciones y perspectivas para aceptar la diferencia, lo extraño y divergente (Strawson 1995).

- El empoderamiento para llevar la paz a la acción (Lederach 2007; Bush y Folger 1996; Muñoz 2000; López 2000, 2006).

- La comunicación para la paz (Nos Aldás 2007) y noviolenta (Rosenberg 2017) para saber opinar, dialogar, interpelar, incluso discrepar, sin herir a la otra parte.

- La ética del cuidado y la coeducación sentimental (Comins Mingol 2009) para ser capaces de educar en la deconstrucción de roles de género y velar por la igualdad, convirtiendo el cuidado en un valor humano, y no de género.

- Entender el conflicto como positivo, partiendo de la posibilidad de su transformación por medios pacíficos, el cual puede convertirse en oportunidades de aprendizaje (Lederach 2010; París 2009; Iglesias 2008; Novara 2003; Cascón 2001)

- La cooperación (Rapoport 1992), concepto que se hace imprescindible para transformar nuestros conflictos y hacer las paces, pues necesitamos ser capaces de cooperar con la otra parte para el entendimiento, pacto o consenso.

- La competencia social y ciudadana para poder contribuir a la transformación social positiva (Marina 2007, 2010; Marina y Bernabeu, 2007)

- La gestión de los sentimientos, las emociones y el amor (Goleman, 2012; Martínez 2005; 2009), se requiere generar esta clase de sentimientos y emociones positivas para contribuir a las culturas de paz.

- La importancia de la fantasía (Rodari 1976; 1995), la imaginación (Lederach 2007) y la creatividad (Robinson 2016; Herrero 2019; Herrero y Vázquez 2018; París y Herrero 2018).

Por la delimitación y foco de interés de este artículo, me propongo desarrollar solo este último aspecto del enfoque REM que vendría a ser el uso de la fantástica, la imaginación y la creatividad como alternativa a la racionalidad moderna basada, mayoritariamente, en la lógica del desprecio, de la competitividad y de la violencia, presentando y entendiendo, así, la interacción humana de manera más respetuosa, cooperativa y pacífica. En este sentido, se requiere anhelar una sociedad en la que haya desaparecido la guerra y el sistema de destrucción organizada para la resolución de conflictos, así como el espíritu destructivo de marginalización, explotación, violencias e 
injusticias, entre otros. Y desarrollar, por tanto, una cultura de paz, que llegue hasta el cerebro, hasta la conciencia de las personas (López Martínez 2006: 71). Asumimos, tal como mencionamos anteriormente, que uno de los objetivos de la Educación para la Paz desde el enfoque REM es aprender a subvertir los argumentos, por ejemplo, el de que las culturas para la paz deben sustituir a las de la violencia, la guerra, la marginación y la exclusión. La guerra y el uso de la violencia no son la solución a los problemas del mundo y podemos buscar otras alternativas pacíficas mediante nuestra concienciación, voluntad, unión y compromiso. Es decir, se plantea como nuestra responsabilidad la búsqueda de otro tipo de soluciones más creativas y pacíficas. En este sentido, se cuenta con las aportaciones de Rodari (1976, 1995), pedagogo italiano, inventor de fábulas, pacifista, fantástico, quien escribía cuentos e historias con el fin de que pudieran ser útiles para aquellas personas que creen en la necesidad de que la imaginación ocupe un lugar en la educación y a quienes confían en la creatividad y en la fantasía (Rodari 1976: 5). De aquí se interpreta la fantástica como el arte de inventar que tanto necesitamos para la paz, pues se requiere, en la actualidad, imaginarla, fantasearla, inventarla y crearla.

\section{El imaginario de la paz desde el enfoque REM}

Desde diversas investigaciones (Muñoz y López Martínez 2000; Lederach 2007; Herrero Rico 2013; García-González 2019), encontramos que uno de los mayores obstáculos en la educación para la paz es el sentimiento de la imposibilidad de su implementación debido a la incapacidad de mucha gente a imaginar la paz como un proyecto real a llevar a cabo. Se requiere, entonces, desde la educación formal, informal y no formal, imaginar la paz, reconocer el valor de su visualización como paso previo a poder llevarla a la práctica. Al igual que la violencia se encuentra y manifiesta de diferentes formas, directas, estructurales y culturales es posible, asimismo, encontrar diversas formas de paz (Galtung 1993). La cuestión es que estas paces aparecen de forma discreta, sin estridencias, ruidos, escándalo, suelen ser paces silenciosas, cuyas manifestaciones suelen pasar desapercibidas. Sin embargo, no podemos mantenernos mudos y sordos ante estas experiencias y hemos de estar atentos y sensibles de oír y reivindicar sus voces, su existencia. Así, las paces silenciosas han de hacerse notar para dar cuenta de su amplitud y de su gran importancia en la trayectoria del devenir histórico (García-González 2019: 256). Rescatar estas paces es de suma importancia para darnos cuenta de la existencia y la naturalidad de la paz desde distintos espacios, tiempos y actores. Mi interés, es, pues, en este apartado, destacar la paz como una característica natural de las relaciones humanas y de las experiencias cotidianas. 
En este marco, hay una serie de aportaciones que se centran en definir la violencia como la ruptura de la naturalidad de las cosas, considerando, así, la paz como lo natural. Por ejemplo, en La Enciclopedia de la Paz y Conflictos (López Martínez 2004: 1159) se afirma que en la mayoría de los diccionarios de lengua española se habla de violencia cuando se realiza una acción que desemboca en un estado "fuera de lo natural", una ruptura de la armonía y del equilibrio. En este sentido, podríamos decir que la violencia es vivida como la ruptura de un "orden establecido", de una armonía preexistente, de unas condiciones de vida que se suponen que son, originariamente, pacíficas. Asimismo, Martínez Guzmán (2001: 117) define también la violencia como un concepto ligado a fuerza, vis en latín, incluso al sentido de poder, más el sufijo lent que da intensidad a la raíz que acompaña. Así, analizando sus raíces etimológicas, hacer algo de manera violenta sería hacerlo con mucha fuerza, ejerciendo el poder (Martínez Guzmán 2005: 86-87). Según lo expuesto, se interpreta que la violencia es cambiar el estado natural de las cosas usando la fuerza, es la violación de algo o alguien a la fuerza, por ejemplo, lo vemos en conductas tan institucionalizadas socialmente como violar la ley, violar a una mujer, violar un código de conducta, entre otras. Entonces, diríamos que la paz es antecesora a la guerra o la violencia "las capacidades humanas para hacer las paces son más naturales, más básicas u originarias, que las capacidades para ejercer la violencia” (Martínez Guzmán 2005: 90).

Teniendo esto en cuenta, podríamos señalar que cada civilización y cada cultura ha creado sus propias imágenes de la paz, son escasas, pero, aun así, se manifiestan visiblemente en las historias populares, en la literatura, en los cuentos, en las mitologías o utopías, fomentando, a través de ellas, modelos de ser y estar, expectativas y esperanzas (Muñoz 2000a). No obstante, y a pesar de ello, existe mucha incertidumbre a la hora de imaginar y definir la paz, es un concepto abstracto, difícil de determinar al igual que ocurre con muchos otros términos relacionados como podrían ser la felicidad, la armonía, la justicia o la libertad, entre otros. Todos ellos son fáciles de reconocer más por su ausencia que por sus significados en sí mismos (Barash y Webel 2009). En realidad, nadie está en contra de la paz, la paz tiene una tremenda capacidad de conseguir un consenso; todos proponen la paz como meta a alcanzar, pero, al mismo tiempo, cada cual la aprovecha y la manipula para sus propios fines e intereses. En este sentido, no existe, prácticamente, ningún programa político o educativo que no prometa y pretenda lograr la paz. No hay ninguna persona que admita no querer vivir en paz. Vemos, entonces, como uno de los retos que se nos plantea en la educación para la paz es la creación de un imaginario de paz que incluya conceptos e imágenes positivas de la paz, para mantener vivas las esperanzas, la capacidad de decisión, las expectativas y la motivación de todas aquellas personas que quieran comprometerse a implementarla. 
Siguiendo la reflexión sobre el imaginario de la paz aprovecho una vieja fábula que una vez Gandhi (2003) contó a su nieto. El cuento según mi propia traducción dice así:

Érase una vez un rey en la antigua India quien estaba curioso por conocer la paz. El rey llamó a muchos maestros, sabios y adivinos de su reinado para que le explicaran su naturaleza y significado, pero ninguno de ellos pudo darle una respuesta satisfactoria. Entonces un día un filósofo paró en el palacio del rey para preguntar por hospedaje y el rey aprovechó para preguntarle. Este contestó que él no sabía la respuesta, pero le indicó que había un sabio que vivía justo fuera de su reino quien seguro podría mostrarle la naturaleza de la paz. A la mañana siguiente, el rey llamó al viejo hombre quien al oír la pregunta del rey fue a su cocina y le trajo un grano de trigo. Depositando la semilla de trigo en la palma de la mano abierta del rey le dijo: "Mira aquí y encontrarás la respuesta". El rey quedó perplejo, pero debido al orgullo de admitir su poco entendimiento ante el viejo se marchó a su palacio y guardó el grano en una cajita de oro. Cada mañana como si de un ritual se tratara abría la cajita y miraba el grano, pero no encontraba respuesta a su pregunta. Pasaron las semanas y al rey se le rompía el corazón porque no lograba descifrar ningún significado. Al final el filósofo volvió de nuevo a visitar el rey, quien enseguida sacó su cajita de oro con el grano y le preguntó que le explicara. "Es muy simple señor. Cuanto más tiempo tenga su grano guardado para su seguridad, nada pasará, creará raíces y perecerá". Sin embargo, si lo pone en interacción con otros elementos, como el aire, el agua, la luz del sol, crecerá y se multiplicará y pronto tendrá un campo de trigo. Ocurre, entonces, lo mismo con la paz, el filósofo continuó: "Si mantenemos la paz que hemos descubierto en la vida guardada en nuestros corazones, perecerá. Pero si interactúa con los demás elementos, culturas y gentes, se expandirá. Y un día habrá paz alrededor del mundo" (Gandhi 2003: 12-13).

Al analizar el contenido de esta fábula nos damos cuenta de la importancia de la motivación y responsabilidad humana para poner en interacción la paz de uno y una misma con la de los y las demás, así poder sembrar la paz a través de nuestras acciones diarias. Vemos que esta clase de historias enfatizan la importancia de la ética, la moral y los valores y tratan de ayudar a cambiar las imposiciones de nosotros mismos y las miras estrechas de mente que limitan nuestro entendimiento del significado de la vida en general y el de la paz, en particular. Asimismo, nos invitan a fantasear y a imaginar en lo bello de la paz, destacando, la importancia de hacer las paces desde nuestras experiencias personales y cotidianidad, clave en el enfoque REM de Educación para la Paz. Finalmente, esta fábula nos muestra que lo que aprendemos de la experiencia es sabiduría, y la paz, concretamente, necesita ponerse en práctica, en interacción con el resto, adquirir experiencia para que siga fluyendo "Your mind is like a room with many open windows. Let the breeze flow in from all directions but refuse to be blown away by anyone" (Gandhi 2003: 14). Entonces, vemos así, 
también, la necesidad de hacer las paces desde una perspectiva holística, es decir, con uno mismo "intrapersonal", en interacción con los seres humanos "interpersonal" y con la Naturaleza y el cosmos "transpersonal” (Fernández Herrería 1999; Melo de Almeida 2003).

\begin{abstract}
Esta consciência holística permite, portanto, uma consciència cósmica e ecológica que no plano educativo se traduz na superaçao do antigo paradigma, fundado na fragmentaçao da ciência e do conhecimento [...]. Assim, esta visao global da paz e da cultura considera que a funçao educativa, na sua nova interpretaçao, nao é o único objectivo da escola, mas que a sua responsabilidade recai, também, sobre todos os elementos do contexto social e mostra como todas as circunstâncias da vida podem se uma oportunidade para aprender (Melo de Almeida 2003: 124-5).
\end{abstract}

Teniendo lo anterior en cuenta, se trata de definir la paz como un término rico, amplio, positivo y lleno de contenido. Asimismo, la paz debe de ser definida en sí misma y no por comparación con su antagónico, guerra o violencia, como se la ha solido interpretar históricamente. En este sentido, se requiere superar esa falta de contenido palpable que normalmente conlleva esa intuición popular sobre la paz, y crear un imaginario de la paz más natural, completo y positivo (Herrero Rico 2013). Este imaginario nos ayudará, asimismo, a situar la paz como un objetivo posible y viable de alcanzar. De este modo, la educación nos ha de posibilitar la construcción de futuros de paz a través de la visualización de imágenes positivas del futuro que puedan favorecer al cambio personal, social y político. De acuerdo con Muñoz (2000a, 2000b), podríamos decir que en la conciencia humana y en el inconsciente colectivo se impregna la idea de que la paz es necesaria, que no podemos prescindir de ella, que sin ella no habríamos sobrevivido ni evolucionado. Así, la paz se vive cotidianamente en forma de creencias, pensamientos, intenciones y juicios. Por tanto, nos cuestionamos ¿cómo podríamos abordar la paz a través de este imaginario? En este sentido, existen muchos escenarios de búsqueda y respuesta, lo cual podría ser indicativo de su amplia existencia. Hay distintas vías y estrategias posibles a seguir, comentamos, a continuación, algunas de ellas (Muñoz y López Martínez 2000: 32): 1) A través de la palabra y el concepto (cómo hablamos y la pensamos: qué es, por qué, para qué, de dónde viene, cómo la utilizamos); 2) Mediante lo emotivo (cómo la vivimos, evocamos, sentimos); 3 ) Usando el juicio moral (cómo la enjuiciamos y valoramos: positiva, negativa, neutralmente, para justificarla, condenarla, afirmarla o negarla) y 4) Con la praxis (qué hacemos o qué podemos hacer ante su realidad, cómo la implementamos y llevamos a la acción cotidiana). Siguiendo, pues, la investigación de Muñoz (2001) coincidimos, de nuevo, con la idea de paz como una característica de los seres humanos originaria desde épocas remotas, considerándola una realidad 
primigenia en todos los tiempos humanos, en los biológicos e históricos, una condición ligada a los seres humanos desde sus inicios "la paz nos permite identificarnos como humanos" (Muñoz 2001: 21). Esta asunción nos interesa pues volvemos a retomar la propuesta de paz desde un sentido cotidiano e intrínseco a nuestras relaciones interpersonales, aunque, Muñoz matiza esta idea (2001) proponiendo el concepto de paz imperfecta. El autor afirma que podría seguir hablando solo de paz, pero el adjetivo "imperfecta" que le acompaña le sirve para abrir, por un lado, su sentido inacabado, y, por otro lado, para subrayar las distintas definiciones y matices de paz a lo largo del devenir histórico. Efectivamente, la paz no es perfecta, acabada, no es un objetivo alcanzado, por eso su carácter de imperfección, no en sentido negativo sino en sentido procesual, en construcción constante, en búsqueda de su perfección. "La paz imperfecta cambia la percepción que tenemos de nosotros mismos al reconocer que históricamente la mayor parte de nuestras experiencias y realidades han sido pacíficas, por lo que genera esperanza y nos moviliza" (Muñoz 2001: 42). En este sentido, Lederach (2007) propone, asimismo, una cosmovisión de la paz que puede interpretarse a través de su concepto de imaginación moral definida como "la capacidad de imaginar algo enraizado en los retos del mundo real, pero a la vez capaz de dar a luz aquello que todavía no existe" (Lederach 2007: 24). Así, este arte de imaginar nos posibilita lograr nuevos retos, como el de la paz, pues si no imaginas algo, no puedes trabajar para conseguirlo. De este modo, la naturaleza de la imaginación nos encaminará al cambio social pacífico y a la ruptura de los ciclos de violencia (Lederach 2007: 25). En definitiva, cabe destacar la importancia de crear un imaginario amplio y positivo de la paz para posibilitarnos una compresión más real y cercana de lo que la paz significa; y para darnos cuenta de que podemos hacer las paces desde nuestra cotidianidad. Este imaginario nos marca un horizonte al que llegar con nuestra acción comprometida o incluso accidental. Accidental porque a través de nuestro pensar y actuar imaginativo y creativo se encuentran alternativas pacíficas casi por azar, a lo que Lederach (2007: 26) llama serendipia, interpretándola como el descubrimiento espontáneo de cosas que no andas buscando realmente, pero que das con ellas por una especie de suerte o sagacidad.

Reiteramos, entonces, que uno de los objetivos que plantea el enfoque REM de Educación para la Paz es la creación de un imaginario de la paz (Herrero Rico 2013). Este imaginario parte de una relación de conceptos, de expresiones, frases y términos que utilizamos en nuestra vida diaria, pero, entiendo, que ni siquiera somos conscientes de ello, así, subrayamos, una vez más, la naturalidad y cotidianidad de la paz (Herrero Rico 2013):

Podríamos relacionar la paz con la ausencia de guerra o violencia que vendría a ser la concepción negativa de paz. Pero, también, con términos más positivos como con la condición humana (es una persona muy pacífica); 
con la salud (estar saludable, no padecer enfermedad, sería sentirse en paz); con el cuerpo (sentirse bien físicamente nos daría una sensación de paz); con uno mismo (tener un nivel aceptable de autoestima y satisfacción personal, porque has actuado bien ante un hecho o circunstancia o has cumplido con tus obligaciones, llamaríamos estar en paz con uno mismo); con la conciencia, la moral o el sentido del deber (se diría estar en paz con uno mismo); con el mundo en general (tener unas buenas relaciones interpersonales con los demás y un contexto socio-cultural aceptable nos haría, también, sentirnos en paz); con el término reconciliación (cuando se unen de nuevo dos personas o más se dice "Ya han hecho las paces"); con el perdón, pacto, acuerdo, negociación (se diría hacer las paces); con los bellos momentos; con la música; con los olores; con la felicidad; con la familia; con el concepto de justicia, igualdad o equidad (por ejemplo, cuando alguien debe algo a otra persona y le devuelve su deuda se dice "estamos a la paz o en paz"); con la satisfacción de las necesidades básicas (tener para comer, beber, dormir, vestir, y con los recursos necesarios para vivir sin sufrimiento, se diría "vivir en paz"); con la naturaleza (podríamos utilizar expresiones como "qué ambiente tan pacifico"); con el placer o el sexo (podríamos definirlo como la paz física); con el silencio (reina la paz); con la libertad (sentirse en paz) e incluso con la muerte (usamos la frase tan cotidiana que se dice cuando uno muere "descanse en paz").

A través de este imaginario que se interpreta desde el enfoque REM, de esta asociación de imágenes y conceptos podemos tener emociones, ideas, estereotipos, definiciones (más o menos concretas o abstractas, subjetivas o intersubjetivas, personales o culturales) que nos permiten pensar la paz, reconocerla, idearla, imaginarla; así como hablar de ella, definirla, describirla, narrarla; y, también, sentirla, evocarla, reaccionar ante ella y, en su caso, implementarla. De este modo, este imaginario nos permite confirmar la existencia de la paz a través del devenir histórico y presentarla en un sentido más amplio, profundo y cotidiano de lo que inicialmente podríamos pensar.

\section{El fomento de la imaginación y la creatividad como elementos clave de la educación para la paz}

En este apartado se pondrá de manifiesto el valor de la imaginación y de la creatividad como elementos clave de la educación para la paz (Lederach 2007; Sátiro 2011, 2018; Herrero Rico 2018; Martínez 2018; García-González 2019). Creatividad tan importante, y tan dejada de lado por los sistemas educativos, relegada solo a unos pocos, genios, artistas y bohemios. Creatividad que rescatamos como un concepto natural que poseemos todas las personas, que la gozamos desde pequeños y nos es tan útil para nuestro desarrollo y para nuestra adaptación al medio (Herrero Rico 2019: 71), "se parte de la posibilidad de un gen innato, pero sin duda la creatividad es común a todos los seres humanos, 
en mayor o menor medida, y es educable" (López y Sandoval 2018: 80). En este sentido, consideramos la creatividad como un aspecto indispensable para trabajar y potenciar, pues nos puede ayudar, entre otras cosas a: 1) crear nuevos conocimientos e ideas para dar distintas respuestas a inquietudes y proyectos, 2) transformar nuestros conflictos de manera pacífica utilizando nuestro pensamiento divergente y nuestra imaginación moral, así como 3) convertirnos en ciudadanos creativos para poder realizar transformaciones sociales positivas (Herrero Rico 2019: 71), "idear, ilusionar, imaginar, inventar, deben ser verbos a los que se les dé la bienvenida para la construcción de la paz" (Muñoz y López Martínez 2000: 443).

Teniendo esto en cuenta, revalorizamos la creatividad como una cualidad de los humanos "la capacidad humana de generar más, nuevas y mejores ideas" (Sátiro 2011: 136) la cual debe partir de la sencillez y desde nuestras experiencias cotidianas y personales, para facilitarnos afrontar nuestras metas, avatares y desafíos "no hay ningún reto que se sitúe más allá de la capacidad creadora que distingue a la especie humana” (Mayor 2018: 17). Angélica Sátiro (2018: 51) destaca, a su vez, la importancia de la creatividad para la formación de una ciudadanía creativa. Se trata de una línea de creatividad social, que hace un planteamiento de perspectiva sistémica y simultánea: desde el punto de vista interno de la persona (ethos creativo), desde sus interacciones como ciudadana y desde la sociedad. Ella conecta pensamiento, sentimiento y acción, colaborando con el desarrollo de sujetos capaces de imaginación ética (utopía) y que, a la vez, proponen y realizan proyectos micro políticos en sus contextos. Teniendo el diálogo como valor democrático y como método para desarrollar la capacidad de pensar y de actuar, propone metodologías de procesos reflexivos y creativos, que generan acción e innovación social (Sátiro 2018: 51).

De acuerdo a García-González (2019: 244) ponemos de manifiesto que la imaginación es, sin duda, un recurso de especial relevancia para pensar y generar situaciones de paz. Una posibilidad para sortear posibles escenarios de violencia de manera pacífica es mediante el uso de la imaginación. GarcíaGonzález alude al término imaginación ética, que implica la capacidad de invención, pensándola siempre con los demás y dando lugar a la construcción de una identidad comunal y pacífica. La imaginación ética nos ha de posibilitar superar creativamente las lógicas belicistas y concebir la noviolencia y la paz o las paces. Así, la imaginación nos permite dar lugar a otras situaciones originales, nuevas e ingeniosas para poder vislumbrar otra manera de ver la realidad. En este sentido, aunando las propuestas de Sátiro (2018) GarcíaGonzález (2019) consideramos la imaginación como un elemento de cambio y transformación "este cambio implica reeducar y reconstruir formas de pensamiento y de vida" (García-Gonzalez 2019: 245). La imaginación ética plantea la paz como objetivo a lograr, como un nuevo escenario susceptible 
de convertirse en realidad. Se destaca aquí el aspecto de que la imaginación puede traer al presente imágenes que no están ante los ojos, tiene un carácter mágico, a su vez que ético. La imaginación ética implica una imaginación fértil, busca soluciones, arreglar las cosas del mundo con la esperanza de que sean mejores (247). Esta imaginación ética, es a su vez, creativa, pues mirando el presente y analizándolo plantea crear alternativas hacia un mundo mejor. Tiene la capacidad de decir "no" al presente para forjar decisiones de futuro, "así cuando ese clamor es de rechazo e indignación es cuando puede relevarse situaciones adversas mediante la imaginación, para desde ahí dar paso y lugar a un estado de cosas avizoradas como mejores" (248). En este sentido, la imaginación, que llamamos ética, es revolucionaria y reformadora pues nos libera de lo real por indigno, guiándonos hacia lo posible, a lo que da luces para dignificar la vida humana (249). Así, gracias a la imaginación, el ser humano puede transformar, desprenderse de sí mismo y contemplar otros modos de vida, otros pensamientos y abrirse a formas variadas de la humanidad (250). La imaginación potencia nuestras habilidades, destrezas, sagacidades, e ingenio para crear nuevos escenarios posibles de paz. La búsqueda de lo imaginable o lo inimaginable, de lo inesperado y de lo que emerge de la creatividad, es lo que podrá dar luces a diferentes formas y proyectos de paz (258). Esa capacidad imaginativa nos permite el desarrollo de nuestras capacidades de percepción más allá de lo aparente y visible, de lo que nos viene dado. Así, desde ese nuevo espacio poder erigir otra realidad más justa, vivible y pacífica. Estos nuevos horizontes posibles han de construirse para abordar las cuestiones de la humanidad aun con los otros y otras diversos, con los diferentes, con los extraños, con los enemigos. Así, la imaginación, la invención, la indagación creativa son fundamentales para construir la paz en un marco de cultura de violencia (García-González 2019: 258).

Por su parte, la creatividad se interpreta como la capacidad de crear lo que nos parece improbable, o como lo llama Freire (1970) "lo inédito viable", mezcla confusa de la pedagogía de la indignación y la de la esperanza. En este sentido, Lederach (2007) nos abre una nueva luz en cuanto a la capacidad humana de crear más allá de lo consciente y premeditado, como una especie de "sagacidad accidental" específica que tenemos en la experiencia cotidiana y por la que muchas veces, se dan unos descubrimientos casuales, espontáneos o ingenuos capaces de dar un giro a situaciones que hemos de transformar o resolver. Esta capacidad de dar con soluciones fortuitas se llama, como ya hemos mencionado anteriormente, serendipia (serendipity), que en castellano podríamos llamar "azar o chiripa" (Martínez 2018: 35). Así, la creatividad es algo más que un producto, se considera como una fuente para estimular las emociones, activar las fortalezas personales y establecer estrategias de pensamiento y afrontamiento (López y Sandoval 2018: 77). La entendemos, 
así, como un proceso que abarca ser sensible a los problemas, ser capaz de definir las dificultades, identificar el elemento no válido, buscar soluciones, hacer suposiciones y comunicar los resultados (López y Sandoval 2018: 77). Asimismo, nos empodera a ser personas resolutivas, buscando alternativas a los problemas cotidianos y a ser personas más felices. En este sentido, la creatividad nos es de gran utilidad para ayudarnos a contribuir a las culturas de paz, en la búsqueda de alternativas pacíficas para la transformación de los conflictos y en la resolución de problemas "agudiza nuestra imaginación creadora, desde la asunción del desorden y confusión iniciales a partir de la cual, creamos el conocimiento más sistemático" (Martínez 2018: 34). Así, desde la Educación para la Paz de la que venimos hablando nos interesa enfocar la paz como un proceso creativo de "hacer" conflictos para que sean productivos. Así, el sistema educativo debería preocuparse de promover la creatividad desde la infancia y a lo largo de toda la vida, por lo que, si bien es cierto que la creatividad la poseemos como característica humana, ésta requiere entrenamiento y experiencia para poder sernos útil en nuestra cotidianidad (Herrero Rico 2019: 73).

Asimismo, la importancia de incluir la imaginación y la creatividad en la educación interpreto que iría en consonancia con los pilares que la UNESCO propone como los objetivos de la educación del S. XXI (Delors 1996) que serían: 1) Aprender a Conocer, la creatividad nos proporcionaría más habilidades para conocer la sociedad, el medio, la cultura y también lo ajeno, 2) Aprender a Hacer, la creatividad nos proporcionaría habilidades para solucionar los problemas, tomar decisiones, así como los valores propios de los humanos para percibir a los demás y vivir en un contexto social 3) Aprender a Ser, la creatividad nos permitiría mayor autoconfianza, autoestima, auto respeto y motivación para la espontaneidad, la improvisación, para ser nosotros mismos. También a potenciar la escucha activa y el reconocimiento del otro, de la otra y de lo otro, y 4) Aprender a Convivir, la creatividad nos facilitaría desarrollar relaciones sociales más positivas, respetuosas, inclusivas y pacíficas (Herrero Rico 2019: 69-70)

Para trabajar estos objetivos, el enfoque REM de Educación para la Paz se apoya en recursos educativos tales como la novela y el cuento porque con sus narrativas se aprende de manera reflexiva, analítica, a su vez que divertida. No solo entretienen, sino que transmiten valores y determinados códigos éticos, morales y sociales (Jares 1999: 196). Desde distintas investigaciones (Jares 1999; Gandhi 2003; Puig Oliver 2005) se hace constar que, a través de los cuentos, las fábulas, las leyendas y las historias se aprende más y con menos esfuerzos, pues su contenido queda impregnado en la mente de las personas, sus aprendizajes son fáciles de memorizar y perduran en el tiempo, como contraposición a lo que se aprende, memorísticamente, de los libros de textos, 
que suele ser duro de recordar (Herrero y Vázquez 2018: 157). Además, de acuerdo con Puig Oliver (2005: 109) el cuento transmite valores y formas de ser, desde un punto de vista ético y moral, promueve la fantasía, enseña la transformación pacífica de conflictos, socializa y crea un sentimiento de grupo, de pertenencia a una comunidad. A su vez, la mayoría de los cuentos y las fábulas son un deleite para los sentidos, invitando al lector a la imaginación y a confabular la existencia de otros posibles mundos, destacando la bondad y la creatividad del ser humano para superar cualquier obstáculo de manera positiva y pacífica. Todas estas aportaciones que los cuentos proporcionan nos interesan en el marco de este artículo, que no es, sino, revalorizar la imaginación, la fantasía, la creatividad y la utopía para que la humanidad pueda forjar un futuro más sostenible y pacífico en el marco de esta crisis mundial de la Covid-19. En este sentido, podríamos utilizar literatura clásica fantástica o como le llama Alberto Chimat (2020) literatura de imaginación, así como, el cine, tanto largometrajes, cortometrajes como documentales o videos de animación. Los discursos y mensajes que se transmiten, tanto en las narrativas escritas como visuales, potencian la imaginación, tanto de niños como de adultos, y nos motivan a repensar desde la fantasía y la creatividad, otros mundos posibles que nos permitan contribuir a las culturas de paz. Lamentablemente, estos mundos pueden ser interpretados también desde la utopía negativa, en este caso, se llama distopia, que no es sino imaginar el mundo, el futuro desde un punto de vista negativo y pesimista, creyendo que lo que nos espera irá siempre a peor. Por el interés que ocupa este artículo, he seleccionado solo literatura utópica positiva que nos permita vislumbrar escenarios de mayores cotas de bondad y paz entre las personas. Algunas obras clásicas, ordenadas de manera cronológica, podrían ser:

- La Odisea (Homero S. VIII a. c)

- La Eneida (Virgilio S. I a. c)

- La República (Platón 370 a. c)

- Utopía (Tomás Moro 1516)

- La Ciudad del Sol (Tommaso Campanella 1602)

- Las Mil y Una Noche (Geraldine McCaughrean \& Richard F. Burton 1704)

- Los Viajes de Gulliver (Jonathan Swift 1726)

- La Bella y la Bestia (Gabrielle-Suzanne 1740)

- Alicia en el País de las Maravillas (Lewis Carrol 1865)

- Erewhon: O al otro lado de las Montañas (Samuel Butler 1872)

- Mirando atrás: del 2000 al 1887; La Igualdad (Edward Bellany 1888 y 1897, respectivamente)

- $\quad$ Noticias de Ninguna Parte (Morris 1890) 
- La Máquina de Tiempo; Una Utopía Moderna; Men Like Gods (H. G. Wells 1895, 1905 y 1923, respectivamente)

- $\quad$ El Maravilloso Mundo del Mago de Oz (Lyman Frank 1900)

- $\quad$ Peter Pan y Wendy (James M. Barrie 1904)

- Herland (Charlotte Perkins Gilman 1915)

- Un Mundo Feliz; La Isla (Aldous Huxley 1932 y 1962, respectivamente),

- $\quad$ El Principito (Saint Exupery 1943)

- $\quad$ El Aleph (Jorge L. Borges 1949)

- $\quad$ El Señor de los Anillos (R. R. Tolkien 1954)

- El principio Esperanza (Ernst Bloch 1954)

- $\quad$ ¡Hagan Sitio! ¡Hagan Sitio! (Harry Harrison 1966)

- La Mano Izquierda Oscuridad y Los desposeidos (Úrsula K. Le Guin 1969 y 1974, respectivamente)

- $\quad$ The female Man (Joanna Russ 1970)

- Ecotopía (Ernest Callenbac 1970)

- Momo; La Historia Interminable (Michael Ende 1973 y 1979, respectivamente)

Algunas obras de más reciente actualidad, ordenadas de manera cronológica, podrían ser:

- $\quad$ El Color de la Magia (Terry Pratchett 1983)

- La Cultura (Ian M. Banks 1987)

- $\quad$ Elmer (David McKee 1989)

- Tiempos de Arroz y Sal (Kim Stanley Robinson 2002)

- Brave Story (Miyuki Miyabe 2003),

- Jonathan Strange y el Señor Norell (Susan Clarke 2004)

- Arqueologías del futuro: el deseo llamado utopía y otras aproximaciones de ciencia ficción (Frederic Jameson 2005)

- $\quad$ El Nombre del Viento (Patrick Rothfuss 2007)

- $\quad$ El Hogar de Miss Peregrine para niños peculiares (Ransom Riggs 2011)

- La Caída de los Reinos (Morgan Rhodes 2018)

- Cuentos para entender el mundo (Eloy Moreno 2020)

Finalmente, cabe decir que mucha de la literatura nombrada también está llevada al cine, pero, no obstante, he recopilado algunas películas que he visto recientemente con mi hijo Hache, de 7 años, las cuales considero que nos motivan a imaginar y a fantasear en la posibilidad de un mundo de valores de cultura de paz:

- $\quad$ El Tigre y la Nieve; La Vida es Bella (Roberto Benigni 1986 y 1997, respectivamente) 
- $\quad$ Cadena de Favores (Mimi Leder 2000)

- Las Crónicas de Narnia (Andrew Adamson y Michaek David (Trilogía de 2005, 2008 y 2010, respectivamente)

- Puente hacia Terabithia (Gábor Csupo 2007)

- Arrugas (Ignacio Ferreras 2011)

- Cuerdas (Pedro Solís García 2013)

- Alike (Daniel Martínez Lara 2015)

- Peter Rabbit (Will Gluck 2018)

- Campeones (Javier Freser 2018)

- $\quad$ El Niño que pudo ser Rey (Joe Cornish 2019)

- Dora y la Ciudad Perdida (James Bobin 2019)

- Abominable (Jill Culton 2019)

- Espías con disfraz (Nick Bruno y Troy Quane 2019)

- Jumanji: el Siguiente Nivel (Jake Kasdan 2019)

- Las aventuras del Dr. Doolittle (Stephen Gaghan 2020)

- Onward (Dan Scaulon, 2020)

- $\quad$ Raya y el último Dragón (Don Hall y Carlos López Estrada, 2021)

Subrayamos, entonces, que en el enfoque REM de Educación para la Paz, la imaginación y la creatividad se nos presentan como herramientas para la transformación social positiva "pensar en lo imaginable que surge de la creatividad es lo que podrá dar luces para concebir y favorecer proyectos de paz. La capacidad imaginativa es un acto de creación, pues transciende lo dado para ir hacia lo que está más allá de lo aparente y visible, en busca de estadios mejor" (García- González 2019: 252).

\section{La utopía y la esperanza como gérmenes de un futuro de culturas de paz}

Desde el enfoque REM de Educación para la Paz proponemos no solo la necesidad de usar la imaginación, la fantástica y la creatividad para hacer las paces (Herrero Rico 2012: 53), sino que depositamos nuestra confianza en la utopía y en la esperanza como semillas para crear un futuro más pacífico, un futuro de culturas de paz. No obstante, encontramos que el término utopía tiene distintas connotaciones y algunas de ellas incluso no compartimos por estar demasiado alejadas de la realidad. En este artículo, sin embargo, interpretamos la utopía desde diversos autores (Freire 1970; Boulding 2000; Torres 2001; García-González 2019) quienes definen la utopía como esa realidad anhelada posible de construir con el compromiso de la especie humana. La utopía parte de un paraguas de mundos imaginarios, pero no son imposibles, no son 
fantasmagóricos, sino que buscan implementarse a partir de intentos prácticos para hacer realidad esas quimeras, esos sueños. Sin embargo, frente a la utopía, los seres humanos permanecemos imperfectos y nos resistimos a los cambios, y manifestamos un gran escepticismo aferrándonos a la idea de que no hay nada más por hacer (García-González 2019: 269). Como alternativa a esta quimera humana de resistencia al cambio, definimos la utopía como la máxima motivación humana para la consecución de una meta u objetivo, tal como señalamos anteriormente en palabras de Freire (1970) "lo inédito viable". Torres (2001) da un paso más allá puesto que no solo considera la utopía como viable, sino que la propone como la meta o el horizonte a seguir para el cambio social positivo "recuperar el valor de la utopía como motor de transformación de la sociedad" (Torres 2001: 12), frente a la pasividad, la indiferencia, el conformismo, la generalización de la desidia y la resignación al pensamiento único. En este sentido, Boulding (2000) propone la utopía como un elemento necesario para motivar a las personas a nutrirse de visiones positivas de cómo las cosas deberían ser. Así, "estas visiones que representan las utopías se convierten en horizontes normativos, metas o desafíos que nos ayudarían a hacer las paces" (Boulding 2000: 29). La idea de utopía es, en un sentido profundo, una crítica al presente, un escape de la realidad para ir a un lugar mejor. Así, la utopía se nos presenta como un recurso para el cambio social positivo, lejos de la violencia y de la injusticia y hacia un orden social humano (Boulding 2000, Torres, 2001, García-González 2019). El camino de la utopía es difícil en niveles macro, pero a pequeña escala puede ser un buen desafío (Boulding 2000: 29). En este sentido, comenta Boulding (2000) que es irónico que utopía que fue definida por Thomas More en 1516 como "ningún lugar" se haya convertido, en la actualidad, sinónimo de "un vuelo desde la realidad" (Boulding 2000: 30).

García-González (2019) destaca, asimismo, que las utopías son, a su vez, un recurso excelente en la educación para la paz. Según la autora nos ayudan a plantear situaciones imaginativas que buscan posibilidades nuevas enmarcadas en ideales morales que estructuran las identidades pacíficas. Se busca con ello, insertar lo posible en lo real para desde ahí imaginar la paz (García-González 2019: 253). La utopía sugiere un modelo de sociedad ideal proyectado hacia el futuro que cuestiona el presente (254). Se trata de abrir el campo de lo posible más allá de lo actual y lo presente para pensar de otro modo el ser y la realidad social.

La utopía se nos presenta como imagen anticipada del porvenir enraizado en la realidad y con una dimensión ética que supone la convicción de que hay que saber de alguna manera lo que debe ser para juzgar lo que es y hacia donde es preciso ir. La utopía señala el fin y la meta, y desde ahí se considera como criterio de juicio que comienza con la crítica de la realidad que impulsa a la acción (García-González 2019: 255). 
Entonces, vemos que, desde la perspectiva de la educación y de la cultura de paz, la utopía representa esfuerzos para desarrollar maneras para que las gentes podamos vivir juntos de formas noviolentas. Para ello, se hace necesario la creatividad en la búsqueda de alternativas, que nos permitan imaginar "al otro" o a "lo otro" cómo podría ser mejor en el mañana. En este sentido, algunos autores (Ferreira Calado 2004; Jares 2005) consideran a Freire como un forjador de utopías, la cual interpretan como la máxima motivación del ser humano para posibilitar su acción con el fin de cambiar la realidad opresiva e injusta "aventurarse en este camino para la construcción de veredas libertarias preñadas de utopía" (Ferreira Calado 2004: 53).

Actualmente, en esta situación de crisis generalizada (sanitaria, económica, educativa, social) provocada por la pandemia global de la Covid-19, destacamos que la utopía nos podría brindar la habilidad de imaginar algo diferente y mejor que lo que existe, y se nos presentaría como un aspecto crucial para la posibilidad del cambio social deseado en cuanto nos muestra un objetivo deseable donde llegar. Como ya nos decía Lederach (2007) si no visionas algo tampoco puedes trabajar para conseguirlo, por lo que, ese quehacer utópico podría motivarnos a vislumbrar un futuro más igualitario, sostenible y pacífico para la humanidad, y aunar esfuerzos comunes por encaminarnos a alcanzarlo. Todavía hay esperanza y anhelo de que algún día nos comportemos más responsablemente y establezcamos una comunidad global basada en las necesidades del planeta y de los habitantes que en el habitan, una sociedad planetaria que sea justa, sostenible y no caracterizada por la violencia (Barash \& Webel 2009: 2).

Las mujeres y los hombres tenemos capacidades distintivas absolutamente desmesuradas, ya que somos capaces de pensar, de imaginar, de anticiparnos, de innovar... ¡de crear! Y, esta facultad creadora, no sólo define a todo ser humano sin distinción, sino que, muy especialmente, constituye nuestra esperanza (Mayor 2018: 13).

Así, en estos tiempos de la Covid-19 la ciudadanía mundial ha mostrado solidaridad(donacioneseconómicas, decomida, dematerial sanitarioa hospitales, entre otros), cooperación (se han cedido espacios públicos y privados para que sirvieran de hospitales, gente ha confeccionado mascarillas para donarlas gratuitamente, por nombrar algunos ejemplos), políticas sociales (ayudas a los colectivos vulnerables, ayudas a los gremios más desfavorecido, se han congelado los desahucios, no se ha cortado la luz por impagos), reconocimiento (se ha aplaudido en España la labor del personal sanitario todos los días a las veinte horas desde balcones y ventanas) y otros valores, como la imaginación y la creatividad, han surgido de manera sobrevenida para hacer cosas nuevas, diferentes y llevar, con buen humor, el confinamiento, la crisis y la soledad de 
la pandemia. Se ha percibido, asimismo, una mayor concienciación en el hecho de que la humanidad es una y que unidos, podemos salir de las adversidades, frases como Juntos podemos, Todo va a salir bien, Quédate en casa, por ti y por todos, han sido eslogan de campañas de sensibilización, publicitarias, así como han decorado ventanas de muchos hogares. Esta actitud planetaria, pacífica y resiliente serían valores que deberían seguir acompañándonos para construir ese futuro de culturas de paz que anhelamos.

We need an essentially new way of thinking if mankind is to survive. Men must radically change their attitudes toward each other and their views of the future. Force must no longer be an instrument of politics... Today, we do not have much time left; it is up to our generation to succeed in thinking differently. If we fail, the days of civilized humanity are numbered (Barash \& Webel 2009: 3).

En este sentido, y siguiendo las propuestas de Freire (1993) se confía en el poder del ser humano para conjuntamente y a través de la acción pacífica y liberadora transformar la realidad social, considerando la esperanza como una necesidad ontológica que nos lleva a la acción y nos mueve para la transformación del mundo. Sin embargo, aunque la esperanza es necesaria, no es suficiente por sí sola para mejorar el mundo, necesita anclar sus propósitos en la práctica real y emancipadora "la esperanza no gana la "lucha", pero sin ella la lucha flaquea y titubea. Necesitamos la esperanza crítica como el pez necesita el agua incontaminada" (Freire 1993: 8). Una esperanza, que interpreto, como la motivación que requerimos para transformar las estructuras y sistemas sociales, como es el educativo, que han quedado obsoletas y no responden a las demandas y retos que nos plantea el nuevo siglo XXI, en general, y la crisis sanitaria de la Covid-19 en particular. Esperanza, en sí, en un mundo más pacífico, más justo, más sostenible y feliz. En este sentido, una importante consigna para la Educación para la Paz que deseamos es educar en la esperanza (Freire 1993; Jares 2005). Teniendo esto en cuenta, desde el enfoque REM de educación para la paz planteamos la necesidad de proponer la esperanza y la utopía como gérmenes para un futuro pacifico. Pero no una esperanza cualquiera, sino una esperanza positiva, contrastada por códigos éticos, basada en criterios de justicia y de respeto a la dignidad e igualdad de las personas "esperanza versus miedo, esperanza versus desilusión serán retos educativos necesarios para encarar nuestras vidas y la propia función educadora" (Jares 2005: 243). Vemos, pues, que la esperanza es una necesidad ontológica "no entiendo la existencia humana y la necesaria lucha por mejorarla sin la esperanza y sin el sueño" (Freire 1993: 8). Parafraseando al poeta palestino Mahmud Darwish (2001) debemos seguir el curso del canto, aunque escaseen las rosas.

En definitiva, en el contexto educativo de creación de paces contamos con el recurso del pensamiento utópico, de la utopía. Y de este pensamiento 
utópico surge la esperanza, al ponernos enfrente un horizonte mejor que alcanzar (García-González 2019: 266). Pensar la esperanza en el marco de la utopía nos mantiene en la creencia de la perfectibilidad humana o en la reivindicación y anhelo de una sociedad ideal. Por tanto, el pensamiento utópico, es una filosofía de la esperanza, en donde la esperanza es esencial para cualquier intento de cambio en la sociedad para ser mejor (García-González 2019: 276). Es importante señalar que las posibilidades que hacen el camino de las utopías se vinculan con la esperanza y esa senda se pavimenta mediante la paz (García-González 2019: 280). En cualquier caso, utopía tiene muchas formas y funciones, pero una de las funciones que más nos interesa destacar es satirizar a la sociedad para, alternativamente, describir otra manera más deseable de organizar los asuntos y relaciones humanas. Estas características de la utopía son las que nos interesan, por tanto, en nuestro enfoque REM de Educación para la Paz.

La pedagogía que defendemos [...] es en sí una pedagogía utópica. Utópica, no porque se nutra de sueños imposibles, porque se afilie a una perspectiva idealista, porque implique un perfil abstracto del ser humano, porque pretenda negar la existencia de las clases sociales o, reconociéndola, intente ser una llamada de las clases dominantes para que, admitiendo su error, acepten comprometerse en la construcción de un mundo de fraternidad. Utópica porque "sin domesticar" el tiempo, rechaza un futuro prefabricado que se instalaría automáticamente, sin contar con la acción consciente de los seres humanos. Utópica y esperanzadora porque, pretendiendo estar al servicio de la liberación de las clases oprimidas, se hace y rehace en la práctica social [...] (Freire 1993: 8).

Así, desde el enfoque REM y en el marco de la propuesta de GarcíaGonzález (2019), ponemos el punto de mira en la búsqueda de paz para encontrar rumbos hacia los que dirigirnos, repensando e indagando alternativas posibles desde la imaginación ética, desde la creatividad, desde la esperanza y desde la utopía. Con ello, podremos reformular el futuro a partir del presente hacia nuevas veredas de paz. Las posibilidades de acción humana desde la imaginación ética y creativa son las que idearán nuevas oportunidades y perspectivas a las culturas de la violencia "las cosas no son como son, son cómo pueden ser. Lo real se puede construir desde lo imaginario. Solo desde la utopía se puede mover la realidad. Para mover la realidad hay que situarse más allá de la realidad, la utopía es el punto de apoyo arquimédico" (Ibáñez 1994). De ahí que pensar la esperanza y la paz en los tiempos difíciles e inciertos provocados por la pandemia global de la Covid-19, en los que nos encontramos, involucra la motivación de construir utopías llevadas a cabo en la acción. Utopías que no son ficciones, aunque no tengan una realidad efectiva, su existencia está en proyecto, en la idea de "todavía no", pero nos muestra posibilidades para la esperanza. Utopía fundamentada en la imaginación y en la inventiva 
humana, sin ella, nuestras improntas hacia un futuro mejor se desvanecerían, se perderían en la nada. Así, estos impulsos que nos brinda la utopía abren nuestras mentes y nos empoderan en la búsqueda de mejores situaciones de justicia bienestar, entendimiento y paz (García-González 2019: 281). Concienciarse de la posibilidad de cambio es indispensable en el enfoque REM de Educación para la Paz pues toma en consideración nuestro compromiso y poder que tenemos como seres humanos para hacer las cosas de maneras diferentes a la lógica de la violencia y la exclusión (Herrero Rico 2009; 2012) "sabemos que también somos competentes para la paz, la solidaridad, la integración. Por lo que debemos esperanzarnos, ilusionarnos y empezar a caminar" (Herrero Rico 2012: 54).

Señor minino- comenzó Alicia, con cierta timidez, al no saber muy bien si le gustaría aquel nombre; pero el Gato seguía sonriendo y ello le animó a la niña a continuar (parece que se lo toma bien):

- ¿Podría, usted, indicarme la dirección que debo seguir desde aquí?

- Eso depende -le contestó el Gato- de adónde quieras llegar.

- No me importa adónde...- empezó a decir Alicia.

- En ese caso, tampoco importa la dirección que tomes- le dijo el Gato

- Con tal de llegar a algún lado - acabó de decir Alicia.

- Eso es fácil de conseguir- le dijo el Gato-. ¡No tienes más que seguir andando!

(Lewis Carroll, Alicia en el país de las Maravillas, cap. VI)

A modo de conclusión cabe decir que este artículo pone el énfasis en el valor de la imaginación, la creatividad y la utopía para afrontar los desafíos generados ante la crisis mundial de la pandemia de la Covid-19. Se cree que, tanto la creatividad como la imaginación, son competencias que nos permiten adaptarnos, mucho más fácilmente y de una manera empática y resiliente, a las nuevas situaciones y a superar los retos con los que nos iremos encontrando. Asimismo, se considera que hacen posible afrontar estas situaciones de maneras alternativas a las acostumbradas y a poder vislumbrar un futuro desde una mirada positiva y esperanzadora, un futuro en el que la humanidad pueda forjar mayores cotas de bienestar, paz y sostenibilidad. El enfoque REM de Educación para la Paz se compromete a seguir trabajando en este sentido.

\section{Referencias bibliográficas:}

Adams, D. (1992): “El Manifiesto de Sevilla sobre la Violencia”, en Hicks, D. (ed.) (1992): Educación para la Paz. Cuestiones, principios y prácticas en el aula. Madrid, MEC/Morata, pp. 293-295.

Barash, D. \& Ch. Webel (2009): Peace and Conflict Studies, California, Sage 
Publications.

Bastida, A. (1994): Desaprender la guerra. Una visión crítica de la Educación para la Paz, Barcelona, Icaria

Boulding, E. (2000): Cultures of Peace, the hidden side of the History, New York, Syracuse University Press. Folger

Bush, R. A. B. \& F. Folger (1996): La promesa de la mediación. Cómo afrontar el conflicto mediante la revalorización y el reconocimiento, Barcelona, Granica.

Cascón, F. (2001): Educar en y para el Conflicto, Barcelona, Cátedra UNESCO sobre paz y derechos humanos, Universidad Autónoma de Barcelona

Cavin, M. (2006): "Elise Boulding's Rethoric: An Invitation to Peace”, Peace and Change, 31, (3), pp. 390-412.

Chimat,A.(2020): $\quad$ https://www.albertochimal.com/2020/02/06/mundosimaginacion-literatura-fantastica/

Comins Mingol, I. (2009): Filosofía del Cuidar, Barcelona, Icaria.

Darwish, M. (2001): Menos Rosas, Madrid, Hiperión.

Delors, J. (1996). La educación encierra un tesoro. Informe a la UNESCO de la Comisión Internacional sobre la educación para el siglo XXI, Madrid, UNESCO/Santillana.

Ferreira Calado, A. D. (2004): Freire, forjador de utopías, Sevilla, Publicaciones M.C.E.P.

Freire, P. (1970): Pedagogía del oprimido. Montevideo, Tierra Nueva.

Freire, P. (1993): Pedagogía de la Esperanza, México D. F., Siglo XXI.

Fernández Herrería, A. (1999): "Educación global y enfoque transpersonal" en A.A.V.V (eds.) (1999): Homenaje al profesor Óscar Sáenz Barrio. Granada: Grupo Editorial Universitario, pp. 241-262

Galtung, J. (1993): “Paz”, en Rubio, A. (ed.): Presupuestos teóricos y éticos sobre la Paz, Granada, Universidad de Granada, pp. 47-52.

Gandhi, A. (2003): The legacy of Love. My education in the nonviolent way, California, Bay Books.

García-González, D. E (2019): La Paz como Ideal Moral. Una reconfiguración de la filosofía de la paz para la acción común, Madrid, Dykinson.

Goleman, D. (2012). Inteligencia Emocional, Barcelona, Kairós

Herrero Rico, S. (2019): "El desarrollo integral del estudiantado: una propuesta desde la educación para la paz, las artes y la creatividad", en Vernia Carrasco, A. (coord.): Música y Cultura para la Inclusión y la Innovación Educativa, Castellón: SEM-EE y Universitat Jaume I, pp. 59-77.

Herrero Rico, S. (2013): La Educación para la Paz. El enfoque REM (Reconstructivo-Empoderador), Alemania, Publicia.

Herrero, S. y A. Vázquez (2018). La Creatividad en la Educación para la 
Paz: Un camino para descubrir la Filosofía con niños y niñas", en Paris,

S. y S. Herrero (eds): El Quehacer Creativo: un desafio para nuestra cotidianidad, Madrid, Dykinson.

Honneth, A. (1997): La lucha por el reconocimiento. Por una gramática moral de los conflictos sociales, Barcelona, Crítica.

Honneth, A. (2008): Reification. A New Look at an Old Idea, New York, Oxford University Press.

Honneth, A. (2011): La Sociedad del Desprecio, Madrid, Trotta.

Ibáñez, J. (1994): Por una sociología de la vida cotidiana, Madrid, Siglo XXI Iglesias, C. (2008): Educar Pacificando. Una pedagogía de los conflictos,

Santiago de Compostela, Seminario Galego de Educación para a Paz, Fundación Cultura de paz.

Jares, X. R. (1999): Educación para la Paz. Su teoría y su práctica, Madrid, Popular.

Jares, X. R. (2005): Educar para la verdad y la esperanza. En tiempos de globalización, guerra preventiva y terrorismos, Madrid, Popular.

Lederach, J. P. (2007): La Imaginación moral. El arte y el alma de la construcción de la paz, Gernika-Lumo, Bakeaz.

Lederach, J. P. (2010): Transformació de conflictes: petit manual d'us, Barcelona, Icaria.

López Martínez, M. (2000): “La sociedad Civil por la Paz”, en Muñoz Muñoz,

F. A. y M. López Martínez (eds.) (2000): Historia de la Paz. Tiempos,

espacios y actores, Granada, Universidad de Granada.

López Martínez, M. (2004): Enciclopedia de Paz y Conflictos, Granada,

Universidad de Granada y Junta de Andalucía.

López Martínez, M. (2006): Política sin Violencia. La Noviolencia como humanización de la política, Colombia, UNIMINUTO.

López, O. y Sandoval, C. (2018). La creatividad como fortaleza positiva en el contexto escolar. En París, S y S. Herrero (eds). El Quehacer Creativo: un desafío para nuestra cotidianidad, Madrid, Dykinson, pp. 69-84.

Marina, J. A. (2007). Educación para la Ciudadanía. Madrid, Ediciones SM.

Marina, J. A. (2010). La educación del talento. Barcelona, Ariel.

Marina, J. A. y R. Bernabeu (2007): Competencia Social y ciudadana, Madrid, Alianza.

Martínez Guzmán, V. (2005): Podemos hacer las Paces. Reflexiones éticas tras el 11-S y el 11-M, Bilbao, Desclée De Brouwer.

Martínez Guzmán, V. (2001): Filosofía para hacer las paces, Barcelona, Icaria. Mayor, F. (2018). Prólogo. En París, S y S. Herrero (eds). El Quehacer Creativo: un desafío para nuestra cotidianidad, Madrid, Dykinson, pp. p. 13-20.

Melo de Almeida, M. E. (2003): A Educaçao para a Paz, Prior Velho, Paulinas. 
Muñoz Muñoz, F. A (2000a): "El Re-conocimiento de la Paz en la Historia", Muñoz Muñoz, F. A y M. López Martínez (eds.) (2000): Historia de la Paz: Tiempos, Espacios y Actores, Granada, Universidad de Granada.

Muñoz Muñoz, F. A. (2000b): "La Paz Imperfecta ante un universo en conflicto" en Muñoz Muñoz, F. A y M. López Martínez (eds.) (2000): Historia de la Paz: Tiempos, Espacios y Actores, Granada, Universidad de Granada, pp. 21-66.

Muñoz Muñoz, F. A. (2001): La Paz Imperfecta, Granada, Universidad de Granada.

Muñoz Muñoz, F. A. y M. López Martínez (eds.) (2000): Historia de la Paz. Tiempos, espacios y actores, Granada, Universidad de Granada.

Nos Aldás, E. (2007): Lenguaje Publicitario y Discursos Solidarios, Barcelona, Icaria.

Novara, D. (2003): Pedagogía del "Saber Escuchar", Madrid, Narcea

París Albert, S. (2009): Filosofía de los Conflictos. Barcelona, Icaria.

París, S. y S. Herrero (2018). El Quehacer Creativo: un desafio para nuestra cotidianidad, Barcelona, Dykinson.

Rapoport, A. (1992): Peace. An Idea Whose Times Has Come, Ann Arbor, The University of Michigan Press.

Robinson, K. (2016). Escuelas creativas: La revolución que está transformando la educación, Madrid, Debolsillo.

Rodari, G. (1995): Cuentos por teléfono, Barcelona, Juventud.

Rodari, G. (1976): Gramática de la fantasía. Introducción al Arte de Inventar Historias, Barcelona, Reforma de la Escuela.

Rosenberg, M. (2017). Comunicación NoViolenta. Un Lenguaje de Vida, Barcelona, Acanto.

Sátiro, A. (2018): Ciudadanía Creativa e Infancias: Hilando Mundo en Paz, en París Albert, S y S. Herrero Rico (eds). El Quehacer Creativo: un desafio para nuestra cotidianidad, Madrid, Dykinson, pp 13-20.

Sátiro, A. (2011): Pedagogia per a una ciutadania creativa, en Temps d'Educació, 40, Barcelona, Universitat de Barcelona.

Strawson, P.T (1995): Libertad, resentimiento y otros ensayos, Barcelona, Paidós.

Torres, C. A. (2001) (comp.): La praxis educativa y la acción liberadora de Paulo Freire, Valencia, Instituto Paulo Freire, Denes. 